HUOM! Tämä on alkuperäisen artikkelin rinnakkaistallenne. Rinnakkaistallenne saattaa erota alkuperäisestä sivutukseltaan ja painoasultaan.

Käytä viittauksessa alkuperäistä lähdettä:

Weck, M., Humala, I., Tamminen, P., \& Ferreira, F. A. (2021). Knowledge management visualisation in regional innovation system collaborative decision-making. Management Decision.

https://doi.org/10.1108/MD-01-2021-0064

PLEASE NOTE! This in an electronic self-archived version of the original article. This reprint may differ from the original in pagination and typographic detail.

Please cite the original version:

Weck, M., Humala, I., Tamminen, P., \& Ferreira, F. A. (2021). Knowledge management visualisation in regional innovation system collaborative decision-making. Management Decision.

https://doi.org/10.1108/MD-01-2021-0064

(C) 2021 Emerald Publishing Limited. This AAM is provided for your own personal use only. It may not be used for resale, reprinting, systematic distribution, emailing, or for any other commercial purpose without the permission of the publisher. 


\title{
KNOWLEDGE MANAGEMENT VISUALISATION IN REGIONAL INNOVATION SYSTEM COLLABORATIVE DECISION MAKING
}

\author{
Marina Weck* \\ HAMK Smart Research Unit \\ Häme University of Applied Sciences \\ Visamäentie 35, 13101 Hämeenlinna, Finland \\ marina.weck@hamk.fi \\ Iris Humala \\ Haaga-Helia University of Applied Sciences \\ Ratapihantie 13, 00520 Helsinki, Finland \\ iris.humala@haaga-helia.fi \\ Pia Tamminen \\ HAMK Smart Research Unit \\ Häme University of Applied Sciences \\ pia.tamminen@hamk.fi \\ Fernando A.F. Ferreira \\ ISCTE Business School, BRU-IUL, University Institute of Lisbon \\ Avenida das Forças Armadas, 1649-026 Lisbon, Portugal \\ or \\ Fogelman College of Business and Economics, University of Memphis \\ Memphis, TN 38152-3120, USA \\ fernando.alberto.ferreira@iscte.pt; fernando.ferreira@memphis.edu
}

*Corresponding author. 


\section{ACKNOWLEDGEMENTS}

This work was funded by the OSIRIS Interreg Baltic Sea Region Project - Supporting the Smart Specialization Approach in the Silver Economy to Increase Regional Innovation Capacity and Sustainable Growth (https://www.osiris-smartsilvereconomy.eu). The authors gratefully acknowledge the contributions of and knowledge shared by the panel members: M. Mälly and M. Takala (Regional Council of Häme); M. Nieminen (Vauraus Suomi Ltd.); A. Ranta-Eskola (Arcade Ltd.); P. Repo (“Ikäraati” senior citizens' association); K. Välikangas and K. Vänni (Häme University of Applied Sciences); and J. Yrjölä (City of Riihimäki). The authors also would like to express their gratitude to J. Laurila (ASV Arctic Smart Village Ltd.) and S. Pitkänen (Hämeenlinnan Sisälähetys association/MeKodit) for their availability and the important practical insights they provided during the consolidation phase. 


\title{
KNOWLEDGE MANAGEMENT VISUALISATION IN REGIONAL INNOVATION SYSTEM COLLABORATIVE DECISION MAKING
}

\begin{abstract}
Purpose - This study was developed in response to the need to develop age-friendly smart living environments (SLEs) due to the complex demands placed on society by the ageing of the population. It sought to analyse the potential that knowledge visualisation offers collaborative decision making applied to the development of a multiple criteria framework supporting knowledge management (KM) through knowledge collaboration $(\mathrm{KC})$ and knowledge sharing $(\mathrm{KS})$ in the context of Regional Innovation Systems (RIS).

Design/methodology/approach - Using a socio-technical approach, knowledgeable and experienced representatives of RIS innovation actors were brought together to develop a constructivist multiple criteria framework that integrates knowledge visualisation and collaborative decisionmaking techniques (i.e., cognitive mapping and system dynamics).

Findings - The study introduces a multiple criteria model supporting KM encompassing conditions and practices of RIS innovation actors facilitating and encouraging $\mathrm{KC}$ and $\mathrm{KS}$. The potential for knowledge visualisation in collaborative decision making is explored in great depth and illustrated in a case study setting.

Practical implications - The panel members who participated in this study consider our methodological proposal to be extremely versatile and see great potential for further applications in RIS contexts.

Originality - The combined use of cognitive mapping and system dynamics according to the strategic options development and analysis (SODA) approach offers a holistic and well-informed perspective on the issue in question. The literature reports no prior work of this methodological combination in the same research context.
\end{abstract}

KEYWORDS: Collaborative Decision Making, Cognitive Mapping, Knowledge Management, RIS, Knowledge Visualisation, SODA, System Dynamics.

ARTICLE CLASSIFICATION: Research Paper. 


\section{INTRODUCTION}

The world is changing rapidly. The megatrend of population ageing observed in the majority of both developed and developing countries is deepening concern about the ability of regional innovation actors to build age-friendly Smart Living Environments (SLEs) which seek to tackle the complex needs and preferences of senior citizens. The key to dealing with the changes is successful innovation systems that enable the convergence of diverse technology solutions and service ideas from multiple sources to develop the most innovative initiatives (United Nations (UN), 2018). This necessitates effective knowledge management (KM) in innovation, fostering successful regional innovation systems (RIS) that play a strategic role in the development of regional innovation capacity (Nonaka and Takeuchi, 1995; Plessis, 2007; Andreeva and Kianto, 2012; Asheim et al., 2020).

In practice, an age-friendly SLE represents a living environment that encompasses digital technology solutions integrated with the services that sustain a senior citizen's comfortable, independent, secure, and active life outside institutional care settings and responds to the requirements of the elder care sector (Lui et al., 2009; Weck et al., 2020; Crawley and Hallowell, 2021). In short, the physical space where these services take place, enabled by the Internet of Things (IoT) and information and communication technologies (ICT), is known as SLE for ageing well (Alliance for Internet of Things Innovation (AIOTI), 2019).

Today, SLEs represent a rapidly growing area of innovation initiatives and are becoming a desired reality. Currently, a major challenge is how to incorporate age-friendly SLEs in the infrastructural or built environment, and technical, financial, administrative, and social network, producing community-driven and customer-oriented services (Topo, 2015; Rinkinen et al., 2016; Kurkela et al., 2017). To tackle this challenge, most innovation efforts need to be extended to an interorganisational level, because no single actor can produce the streams of innovation required. Seamless collaboration and knowledge sharing (KS) between different government and non-government actors or organisations play a vital role in providing an adequate supply of essential services shaping SLEs such as continuous activity and health monitoring, early detection of risk events and cognitive decline, home rehabilitation and physical activity advisers, companions for outdoor activities, and many other services. Given that collaboration is a prerequisite for knowledge to flow both within and outside organisations ( $c f$. Heisig et al., 2016; Tamminen, 2016), collaboration that aims to advance synergies between organisations' innovation activities and a virtuous exchange of knowledge, including ideas for the most prominent research achievements and development challenges, is viewed as knowledge 
collaboration $(\mathrm{KC})$. In this context, $\mathrm{KS}$ is considered an activity through which knowledge such as information, skills, or expertise is exchanged between people, communities, or organisations (Bukowitz and Williams, 1999; Connelly et al., 2012; Agostini et al., 2020).

$\mathrm{KC}$ and $\mathrm{KS}$ are most critical between elder care givers or service providers, technology producers, and senior citizens to foster and support positive attitudes among the elderly towards digital technology solutions and their acceptance (Ranga, 2018; Weck et al., 2020). It is particularly important that senior citizens are engaged in $\mathrm{KC}$ and $\mathrm{KS}$, and participate actively in decision making that can affect them and their communities by offering a diversity of living experiences and valuable information and expectations regarding their complex health and care needs (Tuckett et al., 2018).

In the case of the Häme region's Regional Innovation Systems (RIS) in Finland, where the present study took place, regional collaboration promotes the region's smart specialisation, encouraging innovation initiatives that address the needs of an ageing population. However, there is a need to improve $\mathrm{KC}$ and $\mathrm{KS}$ among regional innovation actors to enable them to screen and accelerate the uptake of innovative products and services designed for the age-friendly SLE. Recognising the benefits that can result from effective KM in building age-friendly SLEs and their underlying complexity, a multiple criteria framework to support KM needs to be developed as the basis for recommendations for the successful management of knowledge through $\mathrm{KC}$ and $\mathrm{KS}$. Following this, the present study sought to demonstrate the potential that knowledge visualisation holds in collaborative decision making applied in the research case and answer the following research questions:

- What conditions will support KM within regional innovation systems?

- What practices of regional innovation actors, specifically of senior citizens, will facilitate and encourage $\mathrm{KC}$ and $\mathrm{KS}$ ?

The research questions were investigated in the context of the Häme region's RIS, targeting the building of age-friendly SLEs and fostering of $\mathrm{KC}$ and $\mathrm{KS}$ among regional innovation actors. These actors represent the Quadruple Helix $(\mathrm{QH})$ innovation framework (Arnkil et al., 2010) and have different roles (i.e., from local authorities, research and business organisations, and public and private service providers in social welfare and healthcare to financers and associations of senior citizens or end users).

From the methodological perspective, this study assumes a constructivist, process-oriented stance (Belton and Stewart, 2002; Bell and Morse, 2013), proposing the combined use of cognitive mapping and system dynamics (SD) to improve RIS collaborative decision making based on 
knowledge visualisation. Specifically, cognitive mapping allows multiple decision makers to be brought together, dealing with conflicts of interest and uncertainty, which in turn allows complex problems to be visualised and structured more clearly (Eden, 2004; Eden and Ackermann, 2004). System dynamics, in turn, was developed by Forrester (1961), and is based on nonlinear dynamics and feedback control theories. By assuming that individuals are rationally limited, SD models support people's thinking processes through heuristics influenced by a set of psychological factors (Papachristos, 2019), which seems to be an important aspect of knowledge visualisation. The literature reports no previous work on this methodological combination in this study context.

This article's structure is organised as follows. The next section presents an overview of the literature on knowledge and KM in the context of RIS. The methodological background of the techniques applied in the present study is then provided. Section four presents the results and managerial implications of the proposed framework. The final section discusses contributions and limitations, and proposes the grounds for further research.

\section{RELATED LITERATURE}

A remarkable increase in interest regarding the factors underlying regional competitiveness is seen in many scientific fields, and studies on RIS have gained increasing attention from academics, policymakers, and practitioners ( $c f$. Asheim et al., 2020). The RIS approach has been developed to be an instrument for national and regional policymakers to encourage innovation and knowledge creation (Asheim and Coenen, 2005; Crawley and Hallowell, 2021), and is based on the literatures on Marshallian industrial districts, economic geography, innovative surroundings, innovation clusters and national systems highlighting the central role of knowledge, and the interaction between the different agents involved in innovation across the public and private sectors (Cooke et al., 1998; Asheim et al., 2011).

According to Asheim and Coenen (2005, p. 1177), "the regional innovation system can be thought of as the institutional infrastructure supporting innovation within the production structure of a region". In this respect, Cooke et al. (1997, p. 475) regard the concepts of region, system, and innovation as the preface "to an extended discussion of the importance of financial capacity, institutionalized learning and productive culture to systemic innovation", and focus their analysis on institutions, arguing that three institutional components are crucial for the identification of RIS 
capacity: (1) financial; (2) learning; and (3) productive cultures. As key elements of the RIS, institutions support the creation of networks and connect organisations within the system (Whittington et al., 2009; Ferreira et al., 2021; Fernandes et al., 2021).

This study adopts the premise of the most critical institutional component - learning, which regards the ability to rapidly learn and manage knowledge within the RIS as a crucial factor for innovation spread, because innovation and learning are closely related (Cooke et al., 1997). In this regard, Fang et al. (2011) and Fernandes et al. (2021) show that information sharing and joint sensemaking (i.e., knowledge flow) are positively associated with relationship-specific memory (i.e., knowledge stock), and indirectly influence both explorative and exploitative innovation. From the same perspective, the concept of learning regions (cf. Morgan, 1997) implies that innovation and economic growth increasingly depend on the ability of regions to learn and "function as collectors and repositories of knowledge and ideas, and provide an underlying environment or infrastructure which facilitates the flow of knowledge, ideas and learning" (Florida, 1995, p. 528). In this context, knowledge is a key source of innovative initiatives. Knowledge represents research and development in the natural sciences and engineering, scientific activities (surveys, statistics, mapping, etc.), and a wide range of technical, managerial, and social skills and cultural contexts (Cooke, 2005), and it resides "in the minds of knowers" as "a fluid mix of framed experiences, values, contextual information, and expert insight that provides a framework for evaluating and incorporating new experiences and information" (Davenport and Prusak, 1998, p. 5). It originates from knowledge creation as a result of R\&D efforts in firms, research laboratories and universities, and interactive processes and flows between actors inside a RIS, as well as from sources outside the region (Karlsson and Johansson, 2006; Ghinoi et al., 2021). These collaborative interactions imply regional actors' KS capacity, which makes it a most important resource for regional innovation performance.

In the context of innovation, $\mathrm{KS}$ is the exchange of expertise that seeks to create or improve products and services of value (Castaneda and Cuellar, 2020), and is also defined as the ability to recognise the value of new information, assimilate it, and apply it for commercial ends (Cohen and Levinthal, 1990; Ghinoi et al., 2021). Sharing knowledge across organisational boundaries can be especially problematic: the more novelty knowledge includes, the more challenges can be found in sharing it (Nonaka and Takeuchi, 1995; Tyre and von Hippel, 1997). The process is also affected by informal routines, norms, and institutions that play an essential role in the form and intensity of the collaboration between organisations (Karlsson and Johansson, 2006). Given the importance of KS, Cabrera and Cabrera (2007) identify the following management practices that are expected to facilitate 
and encourage KS by creating an environment conducive to sharing and positive attitudes towards sharing, as well as by contributing to perceptions of norms for sharing: work design; staffing; training and development; performance appraisal; compensation; culture; and technology. In this study, KS is understood as the capacity to exchange knowledge, technology, and expertise between RIS innovation actors as a result of their knowledge collaboration.

Knowledge sharing and knowledge collaboration are two essential aspects of KM, which is commonly linked to concepts such as continuous collaboration, sharing, learning, innovation, communication, knowledge creation, and discovery ( $c f$. Nonaka and Takeuchi, 1995; Nonaka and Kono, 1998). KM can be defined as the process of creating, sharing, using, and managing an organisation's knowledge and information (Gaviria-Marin et al., 2019). The existing literature offers sufficient theoretical argumentation about the innovation potential of KM. However, KM "is not solely focused on innovation, but it creates an environment conducive for innovation to take place" (Plessis, 2007, p. 24). RIS research on KM covers knowledge creation, knowledge spillovers, knowledge flows, knowledge-intensive business services, different knowledge bases, and other knowledge-related activities, processes, and agents such as R\&D, patents, and clusters (López-Rubio et al., 2020). However, most research has observed these areas theoretically rather than practically. Given the importance of efforts to encourage the $\mathrm{KC}$ and $\mathrm{KS}$ behaviours that are critical components of KM (cf. Chennamaneni et al., 2012), more empirical work is needed that will allow an in-depth exploration of $\mathrm{KC}$ and $\mathrm{KS}$, embedded in and aligned with interactions between collaborating RIS innovation actors. In particular, organisations need approaches and tools to analyse the causal links between factors affecting their KM.

As essential elements of $\mathrm{KM}, \mathrm{KC}$ and $\mathrm{KS}$ are interconnected, interdependent, and increasingly based on the communication process. Without knowledge sharing, knowledge collaboration is meaningless, and increasing the intensity of knowledge collaboration leads to enhanced knowledge sharing. In this context, in which multiple actors contribute their diverse knowledge and expertise to approaching multidimensional research questions, it is worth considering an application of visual tools that foster actors' communication in collaborative decision-making processes. To cope with the underlying complexity of the research context, the present study proposes a combination of knowledge visualisation and collaborative decision-making methods to explore the research questions at hand. 


\section{KNOWLEDGE VISUALISATION IN COLLABORATIVE DECISION MAKING: METHODOLOGICAL ASPECTS}

Knowledge visualisation has been found to be increasingly useful for collaborative decision making (cf. Vail, 1999; Vaz et al., 2021). Motives for using knowledge visualisation are its potential for knowledge creation, knowledge sharing through visual means, learning from visual representations, codifying past experiences visually, or mapping knowledge in conditions of complexity, such as the wide range, roles, and interests of partner organisations like RIS regional innovation actors (Poth, 2018). Knowledge visualisation offers tools to use the creative power of imagery and the possibility of rearrangements and changes, and it can provide potential for the creation of new knowledge in groups, thus enabling innovation (Eppler and Burkhard, 2007; Barão et al., 2021; Vaz et al., 2021).

According to Owen (2015), the aim of collaborative decision making is not to achieve an optimum, compromise, or satisfactory solution, but through their aggregation, understandings reach a significantly more valuable choice than the alternatives any of the decision makers anticipated. Common knowledge is a key source for collaborative decision making. It comprises the intersection of their individual knowledge sets, and it permits individuals to share and integrate aspects of knowledge that are not common to them (Grant, 1996). Davenport and Prusak (1998, p. 5) note that "knowledge is a fluid mix of framed experiences, values, contextual information, and expert insight that provides a framework for evaluating and incorporating new experiences and information. It originates and is applied in the mind of knowers". The more diverse the visons and frames that overlap are, the more a collaborative decision process can bring value and commitment by all decision makers to its implementation (Owen, 2015), thereby avoiding erroneous conclusions (Schiuma et al., 2012).

To support collaborative decision making, many problem structuring methods (PSMs) have been developed over the years ( $c f$. Mingers and Rosenhead, 2004; Rosenhead, 2006; Pérez-Gladish $e t$ al., 2021). In complex and multidimensional decision problems, PSMs have a constructivist epistemological basis, facilitating the combination of objective and subjective elements (Silva et al., 2021). The application of the method provides the core benefit of facilitating decision makers to learn about and better understand the research problem. PSMs help decision makers reflect on their own points of view, values, and objectives, as well as of other individuals (Vaz de Almeida et al., 2019).

Strategic options development and analysis (SODA) is among the most well-known PSMs. It was created by Eden and Ackermann (2001) and is based on cognitive mapping, commonly employed to identify ideas and structure the thinking of various decision makers (Eden, 1988). Cognitive 
mapping can deal with both subjective and objective variables (Ferretti, 2016; Marques et al., 2020), and brings together uncertainty, different perspectives, conflicts of interest, multiple decision makers, and the sharing of their knowledge and experience, facilitating the reorganisation of various lines of thinking, ensuring greater transparency, and allowing decision problems to be structured quite intuitively (Marques et al., 2020; Barão et al., 2021). That said, Ackermann and Eden (2001) note that cognitive mapping techniques are useful in reducing the number of omitted criteria in the decisionmaking processes, as well as in increasing the understanding of the cause-and-effect relationships between variables. As such, cognitive mapping facilitates the structuring of complex decision problems in an easily understood way by supporting communication and promoting mental associations (Ackermann and Eden, 2001; Belton and Stewart, 2002), and cognitive maps are the tools to assist decision-making processes.

Cognitive maps are defined as "the representation of thinking about a problem that follows from the process of mapping" (Eden, 2004, p. 673). Gavrilova et al. (2013, p. 1756) assert that cognitive maps, "as visual tools, facilitate the representation and communication [of knowledge], support the identification and the interpretation of information, facilitate consultation and codification, and stimulate mental associations". These tools have two main functions: first, " $a$ visual representation that can help individuals to elaborate a problem statement, to transform their ambiguous status into an explicit condition, to constrain unnecessary cognitive work, and eventually to create possible solutions"; second, "a thinking tool [...that] supports the processes of generation and elaboration of ideas" (Carlucci et al., 2013, p. 211). Cognitive maps enable individuals' points of view to be visually revealed (Eden, 2004; Castanho et al., 2021).

Cognitive maps as tools for visual representations exhibit the well-established practice of knowledge visualisation and its potential (Vaz et al., 2021). However, knowledge visualisation refers to all interactive graphic means that can be used to develop or convey insights, experiences, methods, or skills. Its main purpose is to support the inherently social processes of creating and sharing knowledge with others, and it is not limited to computer-based images (Eppler, 2013). By utilising visual representations, knowledge visualisation fosters the communication of knowledge between two or more people, emphasises the use of visual metaphors to represent relevant information, and facilitates collaborative dissemination and decision making (Eppler, 2003). In this sense, the application of cognitive maps by managers and decision makers can provide insights into the role of key feedback loops in the system, which might otherwise go undetected using other approaches (alone). Although subjective in nature, cognitive maps promote the exchange of ideas and experiences, 
boost a deeper understanding of decision situations and uncover the cause-and-effect relationships among criteria, allowing questions such as "Why does this happen?" to be answered.

Although extremely versatile and useful, cognitive maps are not free of limitations. Papageorgiou et al. (2012) and Salmeron (2012), for example, argue that these maps are incapable of incorporating the dynamics of real problems, because the maps are incapable of quantifying the intensity of relationships. Given this limitation, fuzzy cognitive maps (FCMs) (Kosko, 1986) have emerged as a well-established alternative tool to represent and analyse system behaviours and dynamics by incorporating elements from fuzzy logic and artificial neural networks in cognitive mapping (Rodrigues et al., 2020). As such, cognitive mapping-based methods and techniques are frequently combined with other types of approach (cf. Belton and Stewart, 2002; Rodrigues et al., 2020) such as SD. The SD approach was developed by Forrester (1961) and supports people's thinking processes through heuristics influenced by a set of psychological factors (Papachristos, 2019). This seems especially interesting in the context of knowledge visualisation. As already pointed out, the literature reports no prior work of this methodological combination in this study context, allowing our proposal to add to the existing literature on KM, knowledge visualisation, and RIS.

\section{STRUCTURING A MULTIPLE CRITERIA FRAMEWORK}

The decision-making process for structuring the multiple criteria framework to support KM through $\mathrm{KC}$ and $\mathrm{KS}$ involved an experienced group of regional innovation actors of the Häme region's RIS. The process was divided into three phases: (1) a pilot study; (2) structuring a framework; and (3) rethinking the framework. The pilot study and framework structuring phases are regarded as the most significant part of the process conducted in December 2019.

The aim was to bring together knowledgeable experts who represented regional innovation actors working actively on various aspects of the region's age-friendly SLEs. Special consideration was given to the diversity of the group representatives or experts. Their diversity in all phases of the process was based on the quadruple innovation helix framework, which describes academia-industrygovernment-civil society interactions (Carayannis and Campbell, 2009) within the RIS. However, when selecting the group representatives, the purpose was not representativeness (Bell and Morse, 2013; Ormerod, 2020) but producing well-focused results to formulate new insights and reflect on the conditions supporting KM. Thus, during the process, the selected experts were acting as decision 
makers, who were in practice researchers, product and service developers, financers, and the local authorities involved in regional economic and business development, as well as representatives of the region's senior citizens' associations.

\section{1. $\quad$ Pilot Study}

Phase I was a pilot study and consisted of a focus group workshop. It was an important part of the research design that allowed for the collection of high-quality data in a social context and an understanding of the research problem from the perspective of the participants (Patton, 2002; Kim, 2010). The workshop aimed to provide a forum for discussion mostly about the establishment of the initial understanding of the complex research context and the identification of the key regional innovation actors actively involved in building SLEs in the region.

Twelve regional innovation actors or representatives of academia, industry, government, and civil society participated in the workshop. The brainstorming technique was applied, with a relaxed and informal approach that encouraged people to come up freely with their thoughts and ideas. Working in two groups, workshop participants employed easy drawings of schemes to best portray ideas and create a representation of what they knew about regional innovation actors building SLEs in the region, and knowledge collaboration and knowledge sharing between them. This is where knowledge visualisation first came into the picture.

In "a more natural environment than that of individual interview because participants are influencing and influenced by others - just as they are in real life" (Casey and Krueger, 2000, p. 11), focus groups enabled open communication, which promoted collaborative decision making and learning among the participants. Researchers adopted the role of "facilitator" and facilitated the participants' collective discussions.

The results of both groups' collaboration and discussion shed light on the key regional innovation actors and especially on the significant contribution senior citizens may make in supporting $\mathrm{KM}$ as the committed and enthusiastic representatives of regional innovation actors. The identified regional innovation actors were considered as having the potential to advance the building of SLEs and were categorised into the following main groups: companies and private services; financial services organisations; city and municipalities; public transport providers; real estate developers and construction companies; condominiums and their boards; the Social Insurance Institution of Finland (KELA) and the tax authorities; educational institutions; voluntary organisations; and parishes. The 
following exemplifies a broad range of introduced senior citizens' engagement practices that may facilitate and encourage $\mathrm{KC}$ and $\mathrm{KS}$ among regional innovation actors: collaboration with city and municipalities, parishes, and students; participating in development of public premises for the opportunities to meet different generations; community housing; age-friendly construction; providing support for personal services, etc. The pilot study thus provided a substantial background that enabled the authors to proceed with a deeper exploration of research questions applying more structured methods in the following phases.

\subsection{Structuring a Visual Framework}

Phase II comprised two knowledge panel meetings with representatives of the key regional innovation actors actively involved in building SLEs in the Häme region. Considerable attention was paid to the selection of the panel members, including reflections on their heterogeneity in terms of professional expertise and gender. Again, the aim was not to achieve representativeness or generalisation, but to ensure that the members of the panel meetings could collaborate effectively as a group of experts working together on issues of common concern (Belton and Stewart, 2002). Indeed, as Bell and Morse (2013, p. 962) note, there is "less emphasis on outputs per se and more focus on process".

The number of panel members was also considered carefully following the suggestion made by Eden and Ackermann (2001, p. 22) (i.e., "the consultant [i.e., the researcher or facilitator] will relate personally to a small number (say, three to ten persons))" or "small groups (ideally of 6-10 key individuals)" (Eden and Ackermann 2004, p. 618). A group of eight decision makers was therefore recruited. These participants shared a broad understanding of the problems and concerns related to the building of SLEs in the region. The greatest recruitment challenge was to commit the recruited experts to participating in the whole process of structuring the conduct of the planned multiple criteria framework in the two knowledge panel meetings. Both panel meetings were process-oriented by nature and each lasted four hours. They were facilitated by one main facilitator/instructor and two assistants.

Knowledge panel meeting I focused on the issues related to KM among the regional innovation actors. To support collaborative decision making and enable all the decision makers to analyse and structure the problem during the panel meeting, the SODA method (Eden and Ackermann, 2001) was applied. The method helped to ensure that each participating expert had a clear understanding of the problem's context and overall structure (Belton and Stewart, 2002), and could express their own 
opinions and perspectives. The general aim was to create a collective cognitive map that sought to represent researched subjects through cause-and-effect relationships (Ackermann and Eden, 2001).

To produce this map, the following trigger question was introduced: "Based on your values and personal experience, how do you describe the 'best' way to support KM?". In practice, the eight panel members were challenged to consider conditions enabling $\mathrm{KC}$ and $\mathrm{KS}$, as well as benefits and barriers. With the help of the "post-its technique" (Eden and Ackermann, 2001), the panel members generated and wrote down 331 ideas or decision criteria (i.e., determinants of $\mathrm{KC}$ and $\mathrm{KS}$ support), using one post-it note for each criterion, and placed them on a whiteboard with the help of two assistants. Afterwards, they were asked to identify determinants that had a negative impact on KM and mark their post-it notes with a minus sign (-). The next task was to organise determinants by key areas of interest, thereby defining the central criteria clusters. In total, six clusters were identified and labelled: "Involved Innovation Actors"; "Motives and Benefits"; "Barriers Issues and Limitations"; "Improvement Actions and Initiatives"; "General Skills, Capabilities, and Competences"; and "Resources and Knowledge-based Activities". This was followed by discussions regarding the most fundamental characteristics of age-friendly SLEs. Three strategic determinants were identified: "Comfortable Life"; "Active Life"; and "Independent Life". The final task of this panel meeting consisted of creating a hierarchy of all the identified criteria within each cluster. This entailed the organising of ideas on post-it notes by order of importance on the whiteboard, i.e., from top - the most important - to bottom - the least important. This visual representation was increasingly helpful for this very important part of the decision-making process, because it required the full engagement of decision makers in generating the collective cognitive map, which also represented a basic multiple criteria framework structure to support KM.

Having finalised the first panel meeting, the collective cognitive map was developed using the Decision Explorer software (www.banxia.com). Figure 1 consists of two parts. First, it introduces the collective cognitive map, which contains all the identified determinants. The arrows in the map structure represent cause-and-effect relationships identified among KM supporting determinants. Second, a snapshot of the map's 3D visualisation is provided, which supports the development of an FCM. Space limitations in this paper prevent the presentation of a clearer version of the map, but the aim is to show the structure in general. A larger version of the map is available on request from the corresponding author.

Knowledge panel meeting II was held with the same group of decision makers participating in the first meeting. The meeting was dedicated to the validation of the developed collective cognitive 
map through analysis and discussion. To convert it into an FCM that showed the real dynamics of the decision problem at hand (Carvalho, 2013), the decision makers were asked to quantify the intensity of cause-and-effect relationships identified in the previous panel meeting by assigning values to all causal links (or arrows) according to the type of relationship between decision criteria (i.e., positive or negative) and using an interval from -1 to 1 (Kosko, 1986). Fuzzy cognitive mapping "is a process that extracts [...] knowledge from [...] participants in order to describe and investigate the problem's model and behavior" (Misthos et al., 2017). Like cognitive maps, FCMs exhibit concepts - or objectives, events, and actions - by nodes, and the cause-and-effect relationships between them by arrows (e.g., Stylios and Groumpos, 1998).

The procedure of assigning intensities was carried out in discussions among panel members with the degrees of intensity being set through consensus. Notably, all the data used were directly provided by the panel members after intense collective discussion and negotiation. Although this procedure is non-linear and inherently subjective, an important feature is that it allows for an interactive exploration of changes in the inputs to the model, so that the impact of such changes can be seen immediately, offering opportunities for further discussion (again, a reflection of the constructivist nature of the framework) (Keeney, 1994; Belton and Stewart, 2002). The importance of group dynamics and negotiation supported by visual representations should be highlighted here, because this allowed decision makers to confront different opinions, learn, and enhance their perceptions, clarifying and improving their understanding of the decision problem at hand. As discussed by Belton and Stewart (2002), the interactive nature of the methods applied allows decision makers to enter decision-making dimensions that would be impossible to achieve with the use of statistical methods alone. Having quantified all cause-and-effect relationships, the Pajek software package (www.mrvar.fdv.uni-lj.si/pajek) was used to create the final FCM of KM supporting determinants. Figure 1, on the right, shows a simplified version of the final FCM. Rotations leading to other angles of the cognitive structure are possible using Pajek (a full version of the structure created, including labels, is also available on request).

In the next stage, an analysis of the final FCM was conducted to identify the degree of centrality of identified determinants. A determinant with a high degree of centrality means that it is very important and has the most significant impact on the system under study (Ribeiro et al., 2017). Table 1 shows the list of support components with the highest degrees of centrality, which, according to Misthos et al. (2017), were calculated by totalling each determinant's indegree and outdegree (the full list of 331 determinants and respective centrality indices is available on request). 


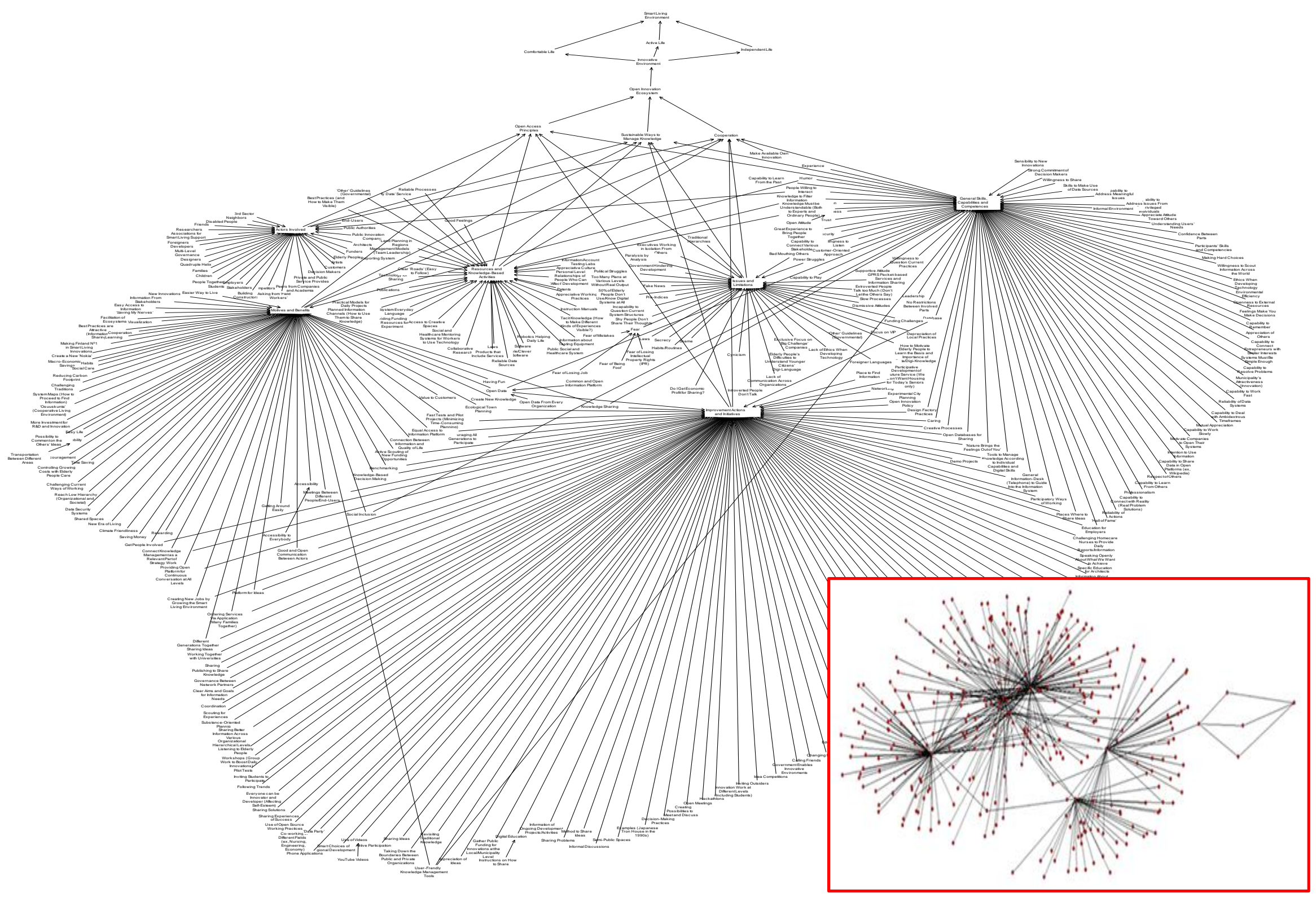

Figure 1. Collective cognitive map and basic structure of the fuzzy cognitive map 
Table 1 Degree of centrality of key determinants of KC and KS as critical components of KM.

\begin{tabular}{lccc}
\hline \multicolumn{1}{c}{ Key determinant/Criterion } & \multicolumn{3}{c}{ Outdegree Indegree Centrality } \\
\hline Improvement Actions and Initiatives & 2.70 & 83.90 & 86.60 \\
General Skills, Capabilities, and Competences & 2.59 & 61.40 & 63.99 \\
Motives and Benefits & 2.70 & 48.30 & 51.00 \\
Resources and Knowledge-Based Activities & 2.70 & 28.20 & 30.90 \\
Actors Involved & 2.60 & 23.40 & 26.00 \\
Barrier Issues and Limitations & 2.40 & 21.10 & 23.50 \\
\hline
\end{tabular}

At the final stage of the second panel meeting, the experts participated in the focus group discussion of the second research question, with a specific focus on the contribution of senior citizens. The nominal group technique (NGT) was applied as a structured method for the expert group's brainstorming session. The method involved quantitative and qualitative data collection from every group member who was closely related to the problem at hand and facilitated the identification of common ground from different perspectives. Specifically, the trigger question in this second meeting was as follows: "Based on your values and personal experience, how can senior citizens contribute to KC and KS among regional innovation actors?", and each panel member had the opportunity to present and defend his/her answer to the trigger question for 15 minutes. After the presentations, the answers were written on a vertical white board visible to everyone. An active group discussion with multi-voting took place to create a ranking of scores assigned to the individual answers obtained, which were later considered in the development of the SD system. As a structured method for group decision making, the NGT application encouraged contributions from everyone and facilitated quick agreement on the study topic (i.e., senior citizens' engagement practices that may contribute $\mathrm{KC}$ and $\mathrm{KS}$ ), including issues and respective solutions.

\section{3. $\quad$ Rethinking and Consolidating the Framework}

The aim of phase III was to analyse and enhance the developed multiple criteria framework using SD. Sedarati et al. (2018) characterise the SD approach as a modelling method that examines internal dynamic interactions, cause-and-effect relationships, and feedback among variables. Better grounded decisions can be made based on a fuller understanding of the dynamics involved by visually representing cause-and-effect relationships between decision criteria and modelling diagrams 
(Assunção et al., 2020). In practice, an SD system is defined as a collection of elements that continually interact over time to form a unified whole. The underlying relationships and connections between the components of a system is called the structure of the system, which includes the initial coefficients/intensities and decision functions quantified by information gathered from the decision $\operatorname{maker}(\mathrm{s})$.

Based on the FCM created in this study, a stock-and-flow diagram (see Figure 2) was generated using the Vensim Personal Learning Edition software (www.vensim.com). The values assigned to all cause-and-effect relationships while constructing the FCM are not visible in Figure 2, but they were included in both the modelling process and the presented stock-and-flow diagram. Once an SD model is constructed and the initial conditions are specified, the structure should be tested for internal coherence based on an initial run (Forrester, 1961; Marques et al., 2020). This initial run allows the behaviour of the different model variables to be analysed over time, offering a source of direct and immediate feedback for decision makers. The SD diagram developed in the present study allowed different simulations to be carried out, allowing the support of KM based on the insights provided by the panel members during phase II.

To understand the scenarios projected in our study more fully and clarify the dynamics of agefriendly SLE variables over time, an initial simulation was run that considered the degrees of intensity initially determined by the participating panel members. The left bottom corner of Figure 2 thus projects the system's behaviour for the initial run, which is the base case and serves as a reference point for the different scenarios projected (size restrictions prevent a better visualization, but an editable version of the entire SD system can be obtained from the corresponding author upon request). Table 2 provides examples of some of the simulations carried out.

The cause-and-effect relationships among the 331 criteria considered in the model or system (see Figure 2) affect the organisation of the set of clusters that form the basis of the dynamics and intensity of causal connections. For example, the results of the initial simulation over a 100-month time horizon show that the high rate of senior citizens' inability to use digital technology has a negative impact on or does not support KM (see the 50\% of elderly people don't use/know digital systems at all determinant in Table 2). However, the digital education determinant has the strongest impact, or greatly facilitates and encourages $\mathrm{KC}$ and $\mathrm{KS}$.

To predict the entire system behaviour over time and determine the intra- and interrelationships, SD principles were applied, and the analysis was divided into two phases: (1) intercluster; and (2) intra-cluster. In the inter-cluster phase, the impacts that different changes in clusters 
have on $\mathrm{KC}$ and $\mathrm{KS}$ were examined. In the intra-cluster phase of analysis, the impacts of changes in criteria within their respective clusters were analysed. Twelve determinants or criteria were selected for analysis (i.e., two criteria from each cluster (see Table 2)), and the SD approach was applied with the aim of examining the interrelationships among 331 determinants and simulating changes in the criteria to understand the impact the variations would have on $\mathrm{KC}$ and $\mathrm{KS}$. To understand how the simulations performed in a realistic context, six scenarios were created to support the inter- and intracluster analyses conducted, including optimistic and pessimistic scenarios. This meant the values of the cause-and-effect relationships were increased by 2, 5, and 10 times, respectively. The information regarding 6 exemplificative simulations (i.e., 3 inter-cluster and 3 intra-cluster simulations) is presented in Table 2. For example, the results show that if the initial value of open innovation policy increases 2, 5 and 10 times, its overall impact on the General Skills, Capabilities and Competences cluster will be 63.6019, 66.3019 and 70.8019, respectively. This, in turn, will impact the overall agefriendliness of the SLE created.

To validate/consolidate the developed visual framework, two interviews were held with external experts from two Finnish private business organisations (i.e., one from the Häme region's RIS and another from the North of Finland), both involved in building age-friendly SLEs. These experts were considered neutral elements because they did not participate in the previous group meetings ( $c f$. Assunção et al., 2020; Marques et al., 2020). Having presented the framework to the experts, the interview discussions focused on the following issues: (1) the comprehensiveness of the determined factors in the visual framework; (2) the representativeness of key groups of RIS innovation actors or experts involved in building age-friendly SLEs; (3) the transferability/generalisation of the results; and (4) the usefulness of the results' visualisation in future decision-making processes. Both interviews lasted one hour. 


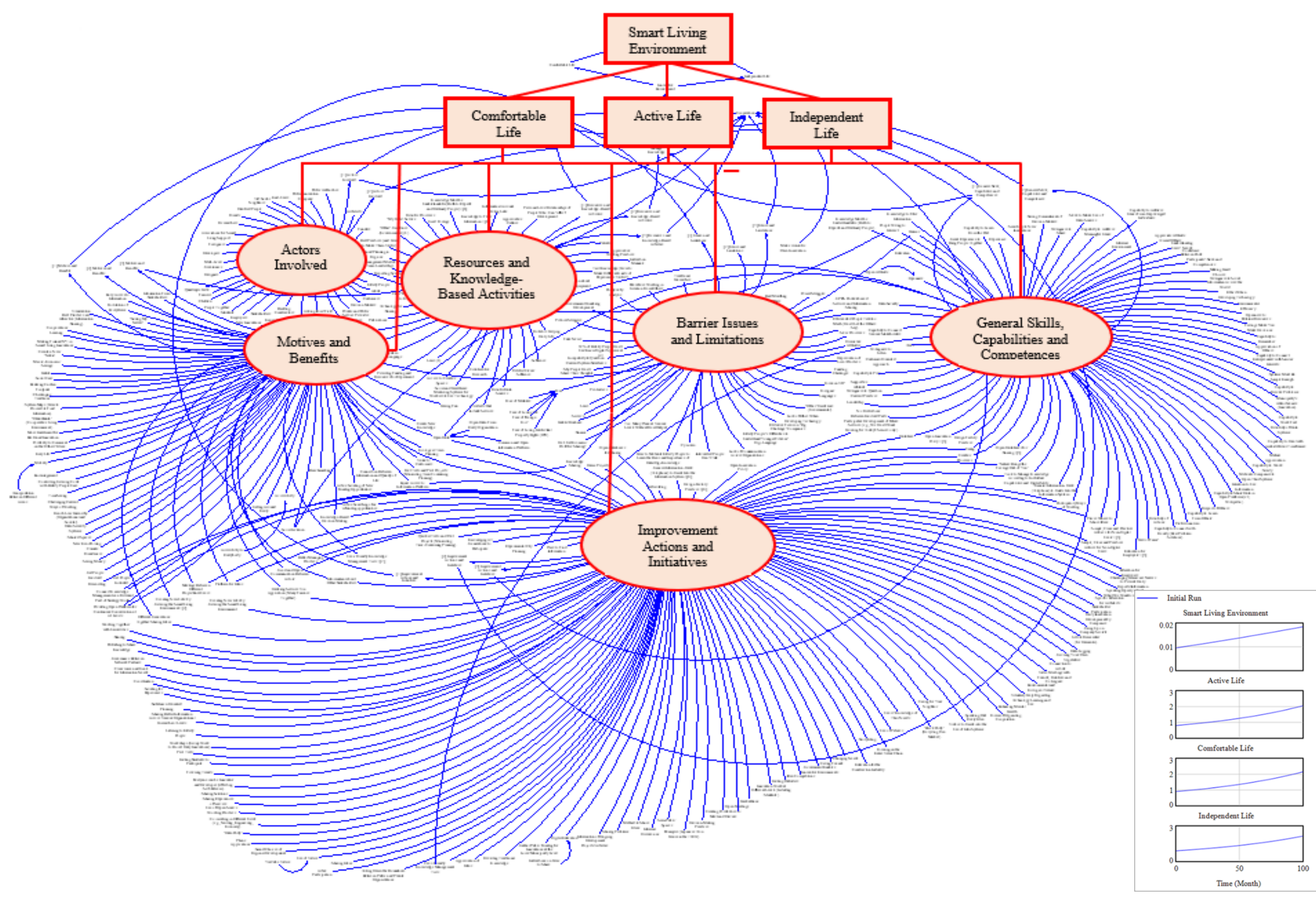

Figure 2 Stock-and-flow diagram based on FCM 
Table 2 Intra- and Inter-cluster Simulation Runs for 12 Selected Determinants (Optimistic Scenario)

\begin{tabular}{|c|c|c|c|c|c|c|c|c|c|}
\hline \multirow[b]{2}{*}{ CLUSTER } & \multirow[b]{2}{*}{ CRITERION } & \multirow{2}{*}{$\begin{array}{l}\text { INITIAL FCM } \\
\text { VALUE } \\
V\end{array}$} & \multirow[b]{2}{*}{$\Delta$} & \multicolumn{3}{|c|}{ INTRA-CLUSTER } & \multicolumn{3}{|c|}{ INTER-CLUSTER (SLE) } \\
\hline & & & & $\mathbf{S} 1$ & S 2 & $\mathbf{S} 3$ & $\mathbf{S} 1$ & S 2 & S 3 \\
\hline \multirow{2}{*}{ Actors Involved } & Elderly People & 1 & $\uparrow$ & 25.4000 & 28.4000 & 33.4000 & 0.0185028 & 0.0185033 & 0.0185041 \\
\hline & Public Authorities & 0.8 & $\uparrow$ & 25.2000 & 27.6000 & 31.6000 & 0.0185028 & 0.0185032 & 0.0185038 \\
\hline \multirow{2}{*}{$\begin{array}{l}\text { Barrier Issues and } \\
\text { Limitations }\end{array}$} & $\begin{array}{l}50 \% \text { of Elderly People Don’t } \\
\text { Use/Know Digital Systems at } \\
\text { All }\end{array}$ & -0.6 & $\downarrow$ & -21.0810 & -22.8810 & -25.8810 & 0.0185025 & 0.0185022 & 0.0185017 \\
\hline & Political Struggles & -0.6 & $\downarrow$ & -21.0810 & -22.8810 & -25.8810 & 0.0185025 & 0.0185022 & 0.0185017 \\
\hline \multirow{2}{*}{$\begin{array}{l}\text { General Skills, } \\
\text { Capabilities and } \\
\text { Competences }\end{array}$} & Receptivity to Innovations & 0.8 & $\uparrow$ & 63.5019 & 65.9019 & 69.9019 & 0.0185028 & 0.0185032 & 0.0185038 \\
\hline & Open Innovation Policy & 0.9 & $\uparrow$ & 63.6019 & 66.3019 & 70.8019 & 0.0185028 & 0.0185032 & 0.0185040 \\
\hline \multirow{2}{*}{$\begin{array}{l}\text { Improvement Actions } \\
\text { and Initiatives }\end{array}$} & $\begin{array}{l}\text { Quicker Tests and Pilot } \\
\text { Projects }\end{array}$ & 0.8 & $\uparrow$ & 85.0999 & 87.4999 & 91.4999 & 0.0185028 & 0.0185032 & 0.0185038 \\
\hline & Digital Education & 0.8 & $\uparrow$ & 85.4464 & 88.8859 & 94.6184 & 0.0185028 & 0.0185032 & 0.0185039 \\
\hline \multirow{2}{*}{ Motives and Benefits } & Easy Access to Information & 0.9 & $\uparrow$ & 48.3988 & 51.0989 & 55.5988 & 0.0185028 & 0.0185032 & 0.0185040 \\
\hline & Get People Involved & 0.9 & $\uparrow$ & 48.3988 & 51.0989 & 55.5988 & 0.0185028 & 0.0185032 & 0.0185040 \\
\hline \multirow{2}{*}{$\begin{array}{c}\text { Resources and } \\
\text { Knowledge-Based } \\
\text { Activities }\end{array}$} & Reliable Processes & 0.9 & $\uparrow$ & 30.2000 & 32.9000 & 37.4000 & 0.0185028 & 0.0185032 & 0.0185040 \\
\hline & Collaborative Research & 0.9 & $\uparrow$ & 30.2000 & 32.9000 & 37.4000 & 0.0185028 & 0.0185032 & 0.0185040 \\
\hline
\end{tabular}

Obs.: $\mathrm{S}_{\mathrm{i}}=$ Simulation Run $i ; \Delta_{\mathrm{s} 1}=|v * 2| ; \Delta \mathrm{s}_{2}=|v * 5| ; \Delta \mathrm{s}_{3}=|v * 10|$.

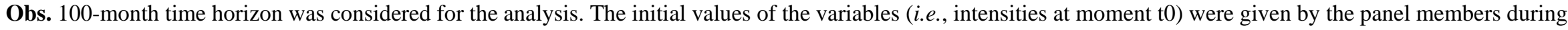
the 2nd group meeting. As an aggregation procedure, we used the following formula (1):

$$
\operatorname{Stock}(t)=\operatorname{Stock}\left(t_{0}\right)+\int_{t_{0}}^{t}\left(\frac{\sum \text { Variables Stock }(t)}{100}\right)
$$

which is an integral that aggregates the intensities of all the criteria linked to a specific cluster plus that cluster's initial value/intensity (Stock (t0)). 
First, both experts provided positive feedback regarding the framework comprehensiveness. This is reflected in the following interview quotation: "The analysis is extremely comprehensive in relation to the time and resources available, and it definitely covers all viewpoints [...] You just cannot say that anything would have been left out" (citing one of the interviewees). Second, having seen the list of experts and their organisations who participated in decision making, the respondents considered that the experts involved in the framework development were competent and qualified, and represented relevant organisations from academia, business, policymakers, and civil society/senior citizens' associations. In their opinion, the experts were therefore able to make a valuable contribution to discussions and decision making based on their significant experience and expertise in the problems under analysis. Third, concerning the generalisation of the results, the experts highlighted that "the findings are global and fully transferable at least in Nordic countries, which have rather similar cultures. In my opinion, a comfortable, active and independent life is the most important issue [in terms of age-friendly SLEs]" (also in the words of one of the interviewees). Fourth, the experts regarded the visual representation of the results as particularly useful, because it enabled any practitioner to see very complex issues in one "big picture", thus facilitating decision making.

\subsection{Analysis and Discussion}

Based on the constructivist approach and the combined use of visualisation and collaborative decisionmaking methods, the present study results contribute to an understanding of how RIS regional innovation actors can work together and manage knowledge effectively through $\mathrm{KC}$ and $\mathrm{KS}$ to foster the emergence of ground-breaking ideas, concepts, and scenarios leading to adoptable innovative solutions and create the necessary conditions for their market uptake in building age-friendly SLEs. The comprehensive cognitive structure or multi-criteria framework to support KM is introduced in Figure 1, using cognitive mapping as a methodological technique.

The applied methodology facilitated the aggregation of the different opinions of decision makers with the practical experience and knowledge of the study problems, and the identification in total of 331 determinants or decision criteria, and their cause-and-effect relationships that were closer to reality in terms of impacts on $\mathrm{KC}$ and $\mathrm{KS}$. The impact of all identified factors was estimated by calculating the degrees of centrality, and the most significant determinants are presented in Table 1. The importance of six groups of factors (i.e., conditions and practices) with the most significant impact on $\mathrm{KC}$ and $\mathrm{KC}$ are: Involved Innovation Actors; Motives and Benefits; Barriers and Limitations; 
Improvement Actions and Initiatives; General Skills, Capabilities, and Competences; and Resources and Knowledge-based Activities (see Figure 2).

The largest group of factors is Improvement Actions and Initiatives, which presents the highest centrality index and is directly related to the conditions supporting $\mathrm{KC}$ and $\mathrm{KS}$. It covers 93 identified factors such as working with universities; inviting students to participate; publishing to share knowledge; clear aims and goals for information needs; listening to elderly people; sharing experiences of success; meetings with end users; sharing problems; informal discussions; storytelling; idea competitions; etc. The General Skills, Capabilities, and Competences cluster (in total, 61 factors) and the Motives and Benefits cluster (in total, 59 factors) were identified as also having a considerable impact on the $\mathrm{KC}$ and $\mathrm{KS}$. This finding corroborates important preconditions acknowledged in previous research (cf. Castells, 2007; Faraj et al., 2011; Rifkin, 2014).

The external resources that RIS innovation actors can use in supporting KM are represented by the Resources and Knowledge-Based Activities cluster, relating 33 factors such as technology for sharing, testing labs, access to creative spaces, and collaborative research. To build the comprehensive framework supporting KM, the decision makers decided to include factors that are central in terms of $\mathrm{KC}$ and $\mathrm{KS}$ interactions, and are fundamental to the understanding of $\mathrm{KM}$. In total, 31 factors representing RIS regional innovation actors who play a key role in screening and accelerating the uptake of innovative products and services for building age-friendly SLEs were identified and covered by the Involved Innovation Actors cluster. Additionally, the Barriers and Limitations cluster had a noteworthy negative impact on the KM. This was discussed and incorporated in the structure. Finally, among strategic criteria or factors emphasised by the expert group, criteria such as Comfortable Life, Active Life, and Independent Life corresponded to characteristics of the agefriendly SLE. These strategic criteria were regarded as an important common target of RIS innovative actors for achieving effective $\mathrm{KM}$ and were placed at the top of the structure (i.e., the latter were above all the others).

The study highlights that having accumulated both personal and professional experience, and with more time at their disposal, senior citizens represent enthusiastic and motivated actors in public discussions and show their willingness to be engaged in building age-friendly SLE-related activities in the region. Moreover, the role of senior citizens seems of critical importance, which is confirmed by 21 well-focused suggestions concerning how senior citizens can contribute to the KC and KS in practice. These suggestions include the following examples: "Joining an open discussion group"; "Sharing ideas over an open innovation platform"; "Sharing one's own knowledge on social media"; 
"Allowing access to their own information (e.g., medical data)"; "Participating in development activities"; "Peer-to-peer support when possible"; "Joining the discussion groups of senior citizens" associations"; "Participating in idea exchange meetings with seniors"; and other very practical recommendations.

\section{CONCLUSION}

The present study sought to structure a multiple criteria framework supporting knowledge management, encompassing conditions and practices of RIS regional innovation actors, facilitating and encouraging knowledge collaboration and knowledge sharing in building age-friendly smart living environments. This study adopted a subjective and idiosyncratic perspective, because the nature of the concepts was the outcome of human judgements, perceptions, and emotions that clearly depended on the specific research context. This means that the research results cannot be generalised to other contexts (e.g., other regional ecosystems and targets) without procedural adjustments. However, the richness of results obtained from profound and intense discussions - put forward by the representatives of regional innovation actors with different roles from local authorities, research and business organisations, public and private service providers in social welfare and healthcare to financers and associations of senior citizens or end users - arguably compensates for context-specific theorising. Additionally, the combined use of cognitive mapping and system dynamics according to the SODA approach offered a holistic and well-informed perspective on the research questions. In this regard, the potential of knowledge visualisation in collaborative decision making was explored in great depth and illustrated by two specific PSMs (i.e., FCM and SD). The importance of visual representations was addressed, contributing to the existing literature, which lacks empirical work.

The FCM enabled the identification, clarification, and structuring of determinants and their cause-and-effect relationships in a multiple criteria framework supporting KM. The FCM was enhanced by the SD approach, which facilitated dynamic analysis of links between determinants in a manner consistent with current realities. Bringing together a knowledgeable and experienced group of experts to formulate new insights and reflect on the determinants obtained from the application of cognitive mapping techniques, made it possible to answer the first research question (i.e., What conditions will support KM within regional innovation systems). The application of NGT and multivoting allowed the second question (i.e., What practices of regional innovation actors, specifically of senior citizens, will facilitate and encourage $\mathrm{KC}$ and $\mathrm{KS}$ ?) to be answered. 
In terms of theoretical implications, the study extends the body of empirical research on KM, producing new insights into the conditions and practices for supporting KM through KC and KS in the context of RIS. The cognitive structure or multiple criteria framework was developed based on the insights obtained from the experts who participated in the study, benefiting from their domain-specific knowledge and experience in building age-friendly SLEs, and applying a combined methodological and socio-technical approach. The framework comprises a large set of identified factors that have a significant impact on $\mathrm{KC}$ and $\mathrm{KS}$, and some corroborate the findings of previous research. Despite considerable diversity in the participants' backgrounds, the achieved results are well informed and have a great congruence with regard to the high degree of complexity underlying the questions they discussed.

In practice, the developed multiple criteria framework represents a decision-support tool that can help RIS regional innovation actors meet the current challenges related to the building of agefriendly SLEs. It can be used particularly to evaluate the supportive conditions, as well as the strengths and weaknesses, of KM, and to analyse practices that facilitate and encourage $\mathrm{KC}$ and $\mathrm{KS}$, enabling the screening and acceleration of the uptake of innovative products and services for senior citizens to have a "Comfortable", "Active", and "Independent Life". Additionally, the study specifically addresses the active role senior citizens have and the valuable contribution they make to $\mathrm{KC}$ and $\mathrm{KS}$. As active participants in the innovation process, senior citizens have not been properly studied. Finally, the framework and practical recommendations in terms of senior citizens' participation support regional actors in formulating concrete initiatives, and taking more informed and rational actions to improve $\mathrm{KC}$ and $\mathrm{KS}$.

The empirical investigation of the research questions was challenging, because the concepts of $\mathrm{KC}$ and $\mathrm{KS}$ and a substantial portion of the processes involved are cognitive and therefore abstract in nature (Boer, 2005), and contain emotional aspects of decision making (e.g., Schwarz, 2000; Andrade and Ariely, 2009; Giorgetta et al., 2013). However, the constructivist, process-oriented and complementary approach of the applied methodology allows the continuous making of flexible adjustments and updates, based on new information and knowledge (Ferreira, 2016). In future research, a visual representation of the study results will therefore provide an opportunity to examine the big picture, detect new patterns, and connect elements in a new way by changing the focus and perspectives. It would be of particular interest to extend the scope of research to other challenges related to decision making in building age-friendly SLEs in different contexts. 


\section{REFERENCES}

Ackermann, F. and Eden, C. (2001), "SODA - Journey making and mapping in practice", in Rosenhead, J. and Mingers, J. (Eds.), Rational Analysis for a Problematic World Revisited: Problem Structuring Methods for Complexity, Uncertainty and Conflict, Wiley, Chichester, UK, pp. 43-60.

Agostini, L., Nosella, A., Sarala, R., Spender, J. and Wegner, D. (2020), “Tracing the evolution of the literature on knowledge management in inter-organizational contexts: A bibliometric analysis", Journal of Knowledge Management, Vol. 24, No. 2, pp. 463-490.

AIOTI - Alliance for Internet of Things Innovation (2019) IoT for Smart Living Environments Recommendations for healthy ageing solutions. AIOTI WG05 Smart Living Environments for Ageing Well, April 2019.

Andrade, E. and Ariely, D. (2009), “The enduring impact of transient emotions on decision making”, Organizational Behavior and Human Decision Processes, Vol. 109, No. 1, pp. 1-8.

Andreeva, T. and Kianto, A. (2012), "Does knowledge management really matter? Linking knowledge management practices, competitiveness and economic performance", Journal of Knowledge Management, Vol. 16, No. 4, pp. 617-636.

Arnkil, R., Järvensivu, A., Koski, P. and Piirainen, T. (2010), Exploring Quadruple Helix: Outlining User-Oriented Innovation Models, Final Report on Quadruple Helix Research for the CLIQ project, INTERREG IVC Programme, Work Research Center, University of Tampere, Tampere.

Asheim, B. and Coenen, L. (2005), "Knowledge bases and regional innovation systems: Comparing Nordic clusters", Research Policy, Vol. 34, No. 8, pp. 1173-1190.

Asheim, B., Isaksen, A. and Trippl, M. (2020), “The role of the regional innovation system approach in contemporary regional policy: Is it still relevant in a globalised world?”, Gonzáles-López, M. and Asheim, B. (Eds.), Regions of Innovation Policies in Europe: Learning from the Margins, Edward Elgar Publishing Limited, Cheltenham, UK, pp. 12-29.

Asheim, B., Smith, H. and Oughton, C. (2011), "Regional innovation systems: Theory, empirics and policy”, Regional Studies, Vol. 45, No. 7, pp. 875-891. 
Assunção, E., Ferreira, F., Meidutė-Kavaliauskienè, I., Zopounidis, C., Pereira, L. and Correia, R. (2020), "Rethinking urban sustainability using fuzzy cognitive mapping and system dynamics", International Journal of Sustainable Development \& World Ecology, Vol 27, No. 2, pp. 261-27.

Barão, M., Ferreira, F., Spahr, R., Sunderman, M., Govindan, K. and Meidutè-Kavaliauskienė, I. (2021), "Strengthening urban sustainability: Identification and analysis of proactive measures to combat blight", Journal of Cleaner Production, Vol. 292, pp. 1-15.

Bell, S. and Morse, S. (2013), “Groups and facilitators within problem structuring processes”, Journal of the Operational Research Society, Vol. 64, No. 7, pp. 959-972.

Belton, V. and Stewart, T. (2002), Multiple Criteria Decision Analysis: An Integrated Approach, Dordrecht, Kluwer Academic Publishers.

Boer, N. (2005). Knowledge Sharing within Organizations: A Situated and Relational Perspective. Rotterdam: Erasmus University of Rotterdam.

Bukowitz, W. and Williams, R. (1999), The Knowledge Management Field Book. Upper Saddle River, NJ, Financial Times (FT) Press, Prentice Hall.

Cabrera, E. and Cabrera, A. (2007), "Fostering knowledge sharing through people management practices", The International Journal of Human Resource Management, Vol. 16, No. 5, pp. 720-735.

Carayannis, E. and Campbell, D. (2009), “'Mode 3' and 'Quadruple Helix': Toward a 21st century fractal innovation ecosystem”, International Journal of Technology Management, Vol. 46, No. 3/4, pp. 201-234.

Carlucci, D., Schiuma G., Gavrilova T. and Linzalone, R. (2013), “A fuzzy cognitive map-based approach to disclose value creation dynamics of ABIs", Proceedings of the 8th International Forum on Knowledge Asset Dynamics (IFKAD-2013), 12-14 June, Zagreb, Croatia, pp. 207219.

Carvalho, J. (2013), "On the semantics and the use of fuzzy cognitive maps and dynamic cognitive maps in social sciences", Fuzzy Sets and Systems, Vol. 214, pp. 6-19.

Casey, M. and Kueger, R. (2000), Focus Groups: A Practical Guide for Applied Research, Thousand Oaks, CA, Sage.

Castaneda, D. and Cuellar, S. (2020), "Knowledge sharing and innovation: A systematic review", Knowledge and Process Management, Vol. 27, No. 3, pp. 159-173. 
Castanho, M., Ferreira, F., Carayannis, E. and Ferreira, J. (2021), "SMART-C: Developing a "smart city" assessment system using cognitive mapping and the Choquet integral”, Engineering IEEE Transactions on Engineering Management, Vol. 68, No 2, pp. 562-573.

Castells, M. (2007), "Communication, power and counter-power in the network society", International Journal of Communication, Vol. 1, pp. 238-266.

Chennamaneni, A., Teng, J. and Raja, M. (2012), A unified model of knowledge sharing behaviours: Theoretical development and empirical test, Behaviour \& Information Technology, Vol. 31, No. 11, pp. 1097-1115.

Cohen, W. and Levinthal, D. (1990), "Absorptive capacity: A new perspective on learning and innovation”, Administrative Science Quarterly, Vol 35, No. 1, pp. 128-152.

Connelly, C., Zweig, D., Webster, J. and Trougakos, J. (2012), “Knowledge hiding in organizations”, Journal of Organizational Behavior, Vol. 33, No. 1, 64-88.

Cooke, P. (2005), "Regionally asymmetric knowledge capabilities and open innovation exploring 'Globalisation 2': A new model of industry organization”, Research Policy, Vol. 34, No. 8, pp. 1128-1149.

Cooke, P., Uranga, M. and Etxebarria, G. (1997). "Regional innovation systems: Institutional and organisational dimensions", Research Policy, Vol. 26, No. 4/5, pp. 475-491.

Cooke, P., Uranga, M. and Etxebarria, G. (1998), "Regional systems of innovation: An evolutionary perspective", Environment and Planning A, Vol. 30, pp. 1563-1584.

Crawley, A. and Hallowell, A. (2021), "Smart specialisation: Insights from the North American periphery", Regional Studies, Vol. 55, No. 3, pp. 427-440.

Davenport, T. and Prusak, L. (1998), Working Knowledge: How Organizations Manage What They Know, Boston, MA, Harvard Business School Press.

Eden, C. (1988), “Cognitive mapping”, European Journal of Operational Research, Vol. 36, No. 1, pp. $1-13$.

Eden, C. (2004), “Analyzing cognitive maps to help structure issues or problems”, European Journal of Operational Research, Vol. 159 No. 3, pp. 673-686.

Eden, C. and Ackermann, F. (2001), "SODA - The principles", in Rosenhead, J. and Mingers, J. (Eds.), Rational Analysis for a Problematic World Revisited: Problem Structuring Methods for Complexity, Uncertainty and Conflict, John Wiley \& Sons, Chichester, pp. 20-41.

Eden, C. and Ackermann, F. (2004), “Cognitive mapping expert views for policy analysis in the public sector”, European Journal of Operational Research, Vol. 152, No 3, pp. 615-630. 
Eppler, M. (2003), "The image of insight: The use of visual metaphors in the communication of knowledge", Proceedings of I-KNOW'03, Graz.

Eppler, M. (2013), "What is an effective knowledge visualization? Insights from a review of seminal concepts”, Knowledge Visualization Currents, Vol. 1, pp. 3-12.

Eppler, M. and Burkhard, R. (2007), "Visual representations in knowledge management: Framework and cases", Journal of Knowledge Management, Vol. 11, No. 4, pp. 112-122.

Fang, S., Fang, S., Chou, C., Yang, S. and Tsai, F. (2011), "Relationship learning and innovation: The role of relationship-specific memory", Industrial Marketing Management, Vol. 40, No. 5, pp. $743-753$.

Faraj, S., Jarvenpää, S. and Majchrzak, A. (2011), "Knowledge collaboration in online communities”, Organization Science, Vol. 22, No. 5, pp. 1224-1239.

Fernandes, C., Farinha, L., Ferreira, J., Asheim, B. and Rutten, R. (2021), "Regional innovation systems: What can we learn from 25 years of scientific achievements?”, Regional Studies, Vol. 55, No 3, pp. 377-389.

Ferreira, F. (2016), “Are you pleased with your neighborhood? A fuzzy cognitive mapping-based approach for measuring residential neighborhood satisfaction in urban communities", International Journal of Strategic Property Management, Vol. 20, No. 2, pp. 130-141.

Ferreira, J., Farinha, L., Rutten, R. and Asheim, B. (2021), "Smart specialisation and learning regions as a competitive strategy for less developed regions", Regional Studies, Vol. 55, No. 3, pp. 373-376.

Ferretti, V. (2016), "From stakeholder's analysis to cognitive mapping and multi-attribute value theory: An integrated approach for policy support", European Journal of Operational Research, Vol. 253, No. 2, pp. 524-542.

Florida, R. (1995), “Toward the Learning Region”, Futures, Vol. 27, pp. 527-536.

Forrester, J. (1961), Industry Dynamics, Massachusetts, The MIT Press.

Gaviria-Marin, M., Merigó, J. and Baier-Fuentes, H. (2019), “Knowledge management: A global examination based on bibliometric analysis", Technological Forecasting and Social Change, Vol. 140, pp. 194-220.

Gavrilova, T., Carlucci, D. and Schiuma, G. (2013), "Art of visual thinking for smart business education", Proceedings of the 8th International Forum on Knowledge Asset Dynamics (IFKAD-2013), 12-14 June, Zagreb, Croatia, pp. 1754-1761. 
Ghinoi, S., Steiner, B., Makkonen, T. and Hassink, R. (2021), "Smart specialisation strategies on the periphery: A data-triangulation approach to governance issues and practices", Regional Studies, Vol. 55, No. 3, pp. 402-413.

Giorgetta, C., Grecucci, A., Bonini, N., Coricelli, G., Demarchi, G., Braun, C. and Sanfey, A. (2013), "Waves of regret: A meg study of emotion and decision-making", Neuropsychologia, Vol. 51, pp. 38-51.

Grant, R. (1996), "Toward a knowledge-based theory of the firm”, Strategic Management Journal, Vol. 17, pp. 109-122.

Heisig, P., Suraj, O., Kianto, A., Kemboi, C., Perez-Arrau, G. and Easa, N. (2016), "Knowledge management and business performance: Global experts' views on future research needs", Journal of Knowledge Management, Vol. 20, No. 6, pp. 1169-1198.

Karlsson, C. and Johansson, B. (2006), "Regional development and knowledge”, Electronic Working Paper Series, Paper no. 76, The Royal Institute of Technology, Centre of Excellence for Science and Innovation Studies (CESIS).

Kim, Y. (2010), "The pilot study in qualitative inquiry: Identifying issues and learning lessons for culturally competent research”, Qualitative Social Work, Vol. 10, pp. 190-206.

Kosko, B. (1986), "Fuzzy cognitive maps”, International Journal of Man-Machine Studies, Vol. 24, No. 1, pp. 65-75.

Kurkela, T., Sanaksenaho, P., Suominen, J., Taegen, J. and Vauramo, E. (2017), "Service block as a concept and its application to different types of population centres" (in Finnish), Reports of the Ministry of the Environment, 3/2017. Available at: http://urn.fi/URN:ISBN:978-952-114725-8 [January 2021].

López-Rubio, P., Roig-Tierno, N. and Mas-Tur, A. (2020), "Regional innovation system research trends: toward knowledge management and entrepreneurial ecosystems", International Journal of Quality Innovation, Vol. 6, No. 4, pp. 1-24.

Lui, C., Everingham, J., Warburton, J., Cuthill, M. and Bartlett, H. (2009). "What makes a community age-friendly: A review of international literature", Australian Journal on Aging, Vol. 28, No. 3, pp. 116-121.

Marques, F., Ferreira, F., Zopounidis, C. and Banaitis, A. (2020). “A system dynamic-based approach to determinants of family business growth", Annals of Operations Research. DOI:10.1007/s10479-020-03524-9. 
Mingers, J. and Rosenhead, J. (2004), "Problem structuring methods in action", European Journal of Operational Research, Vol. 152, pp. 530-554.

Misthos, L., Messaris, G., Damigos, D. and Menegaki, M. (2017), "Exploring the perceived intrusion of mining into the landscape using the fuzzy cognitive mapping approach", Ecological Engineering, Vol. 101, pp. 60-74.

Morgan, K. (1997), “The learning region: Institutions, innovation and regional renewal”, Regional Studies, Vol. 31, No. 5, pp. 491-503.

Nonaka, I. and Kono, N. (1998), “The concept of BA: Building a foundation for knowledge creation”, California Management Review, Vol. 40, No. 3, pp. 40-54.

Nonaka, I. and Takeuchi, H. (1995), The Knowledge Creating Company: How Japanese Companies Create the Dynamics of Innovation, New York, Oxford University Press.

Ormerod, R. (2020), "The pragmatic logic of OR consulting practice: Towards a foundational view", Journal of the Operational Research Society, Vol. 71, No. 11, pp. 1691-1709.

Owen, D. (2015). “Collaborative decision making”, Decision Analysis, Vol. 12, No. 1, pp. 29-45.

Papachristos, G. (2019), "System dynamics modelling and simulation for sociotechnical transitions research", Environmental Innovation and Societal Transitions, Vol. 31, 248-261.

Papageorgiou, E., Roo, J., Huszka, C. and Colaert, D. (2012), "Formalization of treatment guidelines using fuzzy cognitive maps and semantic web tools", Journal of Biomedical Informatics, Vol. 45, No. 1, pp. 45-60.

Patton, M. (2002). Qualitative Evaluation and Research Methods, Thousand Oaks, CA, SAGE Publications Ltd.

Pérez-Gladish, B., Ferreira, F. and Zopounidis, C. (2021), "MCDM/A studies for economic development, social cohesion and environmental sustainability: Introduction", International Journal of Sustainable Development \& World Ecology, Vol. 28, No. 1, pp. 1-3.

Plessis, M. (2007), “The role of knowledge management in innovation", Journal of Knowledge Management, Vol. 11, No. 4, pp. 20-29.

Poth, C. (2018), Innovation in Mixed Methods Research. A Practical Guide to Integrate Thinking with Complexity, Los Angeles, SAGE Publications Ltd.

Ranga, M. (2018), "Smart specialization as a strategy to develop early-stage regional innovation systems”, European Planning Studies, Vol. 26, No. 11, pp. 2125-2146. 
Ribeiro, M., Ferreira, F., Jalali, M. and Meidutè-Kavaliauskienè, I. (2017), “A fuzzy knowledge-based framework for risk assessment of residential real estate investments", Technological and Economic Development of Economy, Vol. 23, No. 1, pp. 140-156.

Rifkin, J. (2014), The Zero Marginal Cost Society: The Internet of Things, the Collaborative of Commons, and the Eclipse of Capitalism, New York, Palgrave Macmillan.

Rinkinen, S., Oikarinen, T. and Melkas, H. (2016), "Social enterprises in regional innovation systems: A review of Finnish regional strategies", European Planning Studies, Vol. 24, No. 4, pp. 723741.

Rodrigues, J., Ferreira, F., Pereira, L., Carayannis, E. and Ferreira, J. (2020), "Banking digitalization: (Re)thinking strategies and trends using problem structuring methods", IEEE Transactions on Engineering Management, DOI:10.1109/TEM.2020.2993171.

Rosenhead, J. (2006), "Past, present and future of problem structuring methods", Journal of the Operational Research Society, Vol. 57, No. 7, pp. 759-765.

Salmeron, J. (2012), "Fuzzy cognitive maps for artificial emotions forecasting", Applied Soft Computing, Vol. 12, No. 12, pp. 3704-3710.

Schiuma, G., Carluccia, D. and Sole, F. (2012), “Applying a systems thinking framework to assess knowledge assets dynamics for business performance improvement”, Expert Systems with Applications, Vol. 39, pp. 8044-8050.

Schwarz, N. (2000), "Emotion, cognition, and decision making", Cognition and Emotion, Vol. 14, No. 4, pp. 433-440.

Sedarati, P., Santos, S. and Pintassilgo, P. (2018), "System dynamics in tourism planning and development”, Tourism Planning \& Development, Vol. 16, No. 3, pp. 256-280.

Silva, A., Ferreira, F., Carayannis, E. and Ferreira, J. (2021), "Measuring SMEs' propensity for open innovation using cognitive mapping and MCDA", IEEE Transactions on Engineering Management, Vol. 68. No 2, pp. 396-407.

Stylios, C. and Groumpos, P. (1998), “The challenge of modelling supervisory systems using fuzzy cognitive maps", Journal of Intelligent Manufacturing, Vol. 9, pp. 339-345.

Tamminen, P. (2016), Possibility-Driven Design in Design-driven Organisations. Doctoral Dissertations 235/2016, Aalto University, Finland.

Topo, P. (2015), "Does the physical environment and technology support a person with a memory disorder?" [in Finnish], Gerontologia, Vol. 29, No. 4, pp. 221-235. 
Tuckett, A., Banchoff, A., Winter, S. and King, A. (2018), “The built environment and older adults: A literature review and an applied approach to engaging older adults in built environment improvements for health", International Journal of Older People Nursing, Vol. 13, No. 1, e12171.

Tyre, M. and von Hippel, E. (1997), “The Situated Nature of Adaptive Learning in Organizations”, Organization Science, Vol. 8, No.1, pp. 71-83.

UN - United Nations (2018), Technology and Innovation Report: Harnessing Frontier Technologies for Sustainable Development. Switzerland, UNCTAD.

Vail, E. (1999), “Mapping organizational knowledge: Bridging the business-IT communication gap”, Knowledge Management Review, No. 8, pp. 10-15.

Vaz de Almeida, M., Ferreira, J. and Ferreira, F. (2019), "Developing a multi-criteria decision support system for evaluating knowledge transfer by higher education institutions", Knowledge Management Research \& Practice, Vol. 17, No. 4, pp. 358-372.

Vaz, A., Ferreira, F., Pereira, L., Correia, R. and Banaitis, A. (2021), "Strategic visualization: The (real) usefulness of cognitive mapping in smart city conceptualization", Management Decision, DOI:10.1108/MD-11-2020-1512.

Weck, M., Helander, N. and Meristö, T. (2020), “Active DigiAge: Technology acceptance by the ageing people", International Journal of Telemedicine and Clinical Practices, Vol. 3, No. 3, pp. 223-242.

Whittington, K., Owen-Smith, J. and Powell, W. (2009). "Networks, propinquity, and innovation in knowledge intensive industries", Administrative Science Quarterly, Vol. 54, No. 1, pp. 90122. 